\title{
Sus1, Sac3, and Thp1 mediate post-transcriptional tethering of active genes to the nuclear rim as well as to non-nascent mRNP
}

\author{
JULIA A. CHEKANOVA, ${ }^{1,2}$ KATHARINE C. ABRUZZI, ${ }^{2}$ MICHAEL ROSBASH, ${ }^{2}$ and DMITRY A. BELOSTOTSKY ${ }^{1}$ \\ ${ }^{1}$ School of Biological Sciences, University of Missouri-Kansas City, Kansas City, Missouri 64110, USA \\ ${ }^{2}$ Howard Hughes Medical Institute and Department of Biology, Brandeis University, Waltham, Massachusetts 02454, USA
}

\begin{abstract}
Errors in the mRNP biogenesis pathway can lead to retention of mRNA in discrete, transcription-site-proximal foci. This RNA remains tethered adjacent to the transcription site long after transcriptional shutoff. Here we identify Sus1, Thp1, and Sac3 as factors required for the persistent tethering of such foci (dots) to their cognate genes. We also show that the prolonged association of previously activated GAL genes with the nuclear periphery after transcriptional shutoff is similarly dependent on the Sac3-Thp1-Sus1-Cdc31 complex. We suggest that the complex associates with nuclear mRNP and that mRNP properties influence the association of dot-confined mRNA with its gene of origin as well as the post-transcriptional retention of the cognate gene at the nuclear periphery. These findings indicate a coupling between the mRNA-to-gene and gene-to-nuclear periphery tethering. Taken together with other recent findings, these observations also highlight the importance of nuclear mRNP to the mobilization of active genes to the nuclear rim.
\end{abstract}

Keywords: mRNA export; mRNP; Saccharomyces cerevisiae

\section{INTRODUCTION}

The export of eukaryotic mRNA to the cytoplasm is preceded by nuclear RNA processing. This includes covalent events (capping, splicing, and polyadenylation) as well as the noncovalent addition of hnRNP proteins, which facilitate binding and translocation of mRNA through nuclear pores. There are also elaborate quality-control mechanisms, which monitor the biogenesis of nuclear mRNP (Jensen et al. 2003; Fasken and Corbett 2005). Indeed, Saccharomyces cerevisiae strains bearing temperaturesensitive mutations in genes encoding nuclear processing factors manifest a pronounced nuclear mRNA retention. These genes include poly $(\mathrm{A})$ polymerase PAP1 (Hilleren et al. 2001), the mRNA export receptor MEX67 (Jensen et al. 2001b), and 3'-end processing factors RNA14 and RNA15 (Libri et al. 2002), as well as the components of the nuclear THO/TREX complex SUB2, HPR1, and MFT1 (Jensen et al. 2001a; Libri et al. 2002). Upon a shift to nonpermissive

Reprint requests to: Dmitry A. Belostotsky, School of Biological Sciences, University of Missouri-Kansas City, Kansas City, MO 64110, USA; e-mail: belostotskyd@umkc.edu; fax: (816) 235-5595.

Article published online ahead of print. Article and publication date are at http://www.rnajournal.org/cgi/doi/10.1261/rna.764108. conditions, these strains accumulate mRNA in discrete, transcription-site-proximal foci (hereafter referred to as "dots") that can be visualized by fluorescent in situ hybridization (FISH) with gene-specific probes.

Nuclear mRNA dots can also be observed in wild-type cells under physiological conditions. For example, robust, intense dots arise from a GAL-driven GFP-encoding reporter construct, which bypasses normal 3 '-end processing because it terminates in a hammerhead ribozyme (GALGFP-RZ). Dots also arise from a reporter with a wild-type GAL 3'-UTR (containing GAL1 3'-end formation signals; GAL-GFP-pA) and even from the endogenous GAL1 gene (Dower et al. 2004; Abruzzi et al. 2006). Therefore, dot formation likely reflects a regular feature of gene expression, which is quantitatively increased when nuclear mRNA processing is suboptimal or perturbed. Importantly, both GAL-GFP-RZ and GAL-GFP-pA reporters give rise to dots containing RNA that is largely post-transcriptional (i.e., non-nascent). This is because the dots are spatially distinct from their transcription sites and because they persist long after the transcriptional shutoff (Abruzzi et al. 2006). Moreover, dots remain adjacent to their transcription sites during the shutoff.

Intriguingly, dot formation correlates with the tendency of active genes to associate with the nuclear periphery 
(Abruzzi et al. 2006), which suggests mechanistic links between these two processes. Several mechanisms have been proposed to contribute to the recruitment, capture, and/or subperipheral retention of genes at the nuclear envelope. These include direct interactions between transcriptional activators and nucleoporins (Menon et al. 2005; Schmid et al. 2006), the act of transcription itself (Cabal et al. 2006; Taddei et al. 2006), transcription-associated chromatin remodeling (Brickner et al. 2007), as well as unspecified mRNA- and/or 3'-UTR-dependent interactions (Casolari et al. 2005; Taddei et al. 2006). Our own experiments have also highlighted the importance of $3^{\prime}$-end formation signals on gene-periphery associations. Moreover, these have a strong and parallel influence on dot formation (Abruzzi et al. 2006).

In this study, we conducted a FISH-based screen for dot tethering factors. Our strategy was based on the assumption that perturbation of the tether(s) between the dot and its gene would probably impact dot morphology. Indeed, we identified Sus1, Thp1, and Sac3 as factors affecting dot morphology as well as the persistent tethering of dots to their cognate genes after transcriptional shutoff. This strongly implicates the Sac3-Thp1-Sus1-Cdc31 complex in posttranscriptional dot-gene tethering. Remarkably, the association of the endogenous GAL1 locus to the nuclear periphery previously has been shown to be inhibited by the absence of this same complex (Cabal et al. 2006; Drubin et al. 2006). However, its dual association with the transcription coactivator SAGA as well as with NPCs has precluded discriminating between a transcriptional and a posttranscriptional role of the complex. The findings reported here favor the latter, because the retention of previously activated (but transcriptionally silent) $G A L$-promoter-driven reporter genes at the nuclear periphery similarly requires the activity of these three proteins. The parallel findings on these two tethering phenomena underscore the mechanistic coupling between the mRNA-to-gene and gene-nuclear periphery interactions and emphasize the contribution of post-transcriptional events to both processes.

\section{RESULTS}

\section{Components of the Sac3-Thp1-Sus1-Cdc31 complex affect the morphology of nuclear mRNP dots arising because of the bypass of the 3 -end processing}

To conduct a FISH-based screen for the dot tethering factors, we used a strain containing a single-copy, integrated reporter gene construct. It contains a TDH3promoter-driven GFP ORF followed by a ribozyme (RZ) $3^{\prime}$-end formation sequence (TDH-GFP-RZ). The construct gives rise to a robust, constitutive nuclear dot in almost $100 \%$ of cells, which is visualized by FISH (note that this construct generates negligible amounts of GFP protein). We then examined dot morphology in a focused sublibrary of viable deletions (Tong et al. 2001), which was compiled via an extensive manual survey of genes implicated in mRNA biogenesis, processing, and export (Table 1).

Deletion of SUS1 resulted in a striking enlargement and/ or fragmentation of the dot (Fig. 1A,B), reproducibly observed in $\geq 80 \%$ of cells. Importantly, these effects were not dependent on the specific construct or on its integration site, because substituting the conditional GAL1 promoter for the $\mathrm{TDH} 3$ promoter as well as placing the reporter at a different genomic location led to an identical dot enlargement and fragmentation in an susls background (Fig. 1C). Moreover, simultaneous visualization of the GAL-GFP-RZ locus using TetR-GFP bound to a tandem array of 448 Tet operators integrated $<5 \mathrm{~kb}$ from the reporter construct (TetR-GFP/TetO 448 system) showed that one major dot was always adjacent to the reporter gene (Fig. 1C). (In these and subsequent experiments, the nuclear periphery was simultaneously visualized using Nup49-GFP, which by itself has no effect on the dot morphology.) This suggests a precursor-product relationship between the primary, locus-proximal mRNA dot and secondary dots that break off and diffuse away. Introducing a wild-type (WT) copy of the SUS1 gene into the sus1A strain fully rescued this phenotype (Fig. 1D) as well as the other associated phenotypes described below.

Sus1 is a component of the Sac3-Thp1-Sus1-Cdc31 complex, which is anchored to the nuclear pore via an Sac3-Nup1 interaction (Fischer et al. 2002). Sus1 also copurifies with the transcriptional coactivator SAGA and is believed to mediate transcription-coupled mRNA export (Rodriguez-Navarro et al. 2004). Indeed, loss of Sus1 compromises transcription of a subset of SAGA-regulated genes and also leads to increased accumulation of poly $(\mathrm{A})^{+}$ RNA in the nucleus (Fischer et al. 2002, 2004; RodriguezNavarro et al. 2004). Because the TDH3 promoter used to drive the GFP-RZ reporter is SAGA-regulated (Basehoar et al. 2004), we determined whether the sus $1 \Delta$ effect on dot morphology is principally due to the impaired function of SAGA or of the Sac3-Thp1-Sus1-Cdc31 complex. To this end, we tested by FISH four additional deletion strains missing components of these complexes.

We found that deletions of the SAGA genes GCN5 or SPT20 had no effect on TDH-GFP-RZ dot morphology (Fig. $1 \mathrm{E}, \mathrm{F}$; data not shown). The spt20د mutation causes severe disruption of SAGA complex integrity and function (Grant et al. 1997; Sterner et al. 1999) and prevents Sus1 from associating with the promoter of GAL1 (Kohler et al. 2006). Moreover, the effect of $g c n 5 \Delta$ on transcription is quantitatively identical to that of sus1s (Fig. 3C,D below; Dudley et al. 1999). We therefore conclude that the SAGA complex does not contribute substantially to mRNP dot morphology.

In contrast, deletions of either THP1 or SAC3 genes resulted in effects indistinguishable from those observed in sus $1 \Delta$ cells (Fig. 1G,H), that is, an exaggerated and/or fragmented dot. We conclude that compromising the function of the Sac3-Thp1-Sus1-Cdc31 complex perturbs 
TABLE 1. A sublibrary of viable mRNA export-relevant deletion mutants used in the FISH-based screen

\begin{tabular}{|c|c|c|c|}
\hline Gene ID & Name & Biological process (GO terms) & Description \\
\hline YMR044W & IOC4 & Chromatin remodeling & $\begin{array}{l}\text { Component of a complex (Isw1b) with Isw1p } \\
\text { and loc } 2 p \text { that exhibits nucleosome-stimulated } \\
\text { ATPase activity }\end{array}$ \\
\hline YGL133W & ITC1 & Chromatin remodeling & $\begin{array}{l}\text { Component of the ATP-dependent Isw2-Itc1 } \\
\text { chromatin-remodeling complex }\end{array}$ \\
\hline YIL079C & AIR1 & RNA export from nucleus & $\begin{array}{l}\text { TRAMP complex, also interacts with the } \\
\text { arginine methyltransferase } \mathrm{Hmt} 1 \text { to regulate } \\
\mathrm{Npl} 3 \text {, which modulates } \mathrm{Npl} 3 \text { function in } \\
\text { mRNA processing and export }\end{array}$ \\
\hline YDL175C & AIR2 & RNA export from nucleus & $\begin{array}{l}\text { TRAMP complex, also interacts with the } \\
\text { arginine methyltransferase } \mathrm{Hmt} 1 \text { to regulate } \\
\text { Npl3, which modulates Npl3 function in } \\
\text { mRNA processing and export }\end{array}$ \\
\hline YFL007W & BLM10 & Proteasome assembly & $\begin{array}{l}\text { Found in association with proteasome core } \\
\text { particles, with and without the } 195 \text { regulatory } \\
\text { particle }\end{array}$ \\
\hline YPR057W & BRR1 & Spliceosome assembly & $\begin{array}{l}\text { In null mutant, newly synthesized snRNAs are } \\
\text { destabilized, and } 3^{\prime} \text {-end processing is slowed }\end{array}$ \\
\hline YLR226W & $B \cup R 2$ & Transcription & $\begin{array}{l}\text { Cyclin for Bur1 kinase; transcriptional regulation } \\
\text { through its phosphorylation of RNAPII CTD }\end{array}$ \\
\hline YAL021C & CCR4 & $\begin{array}{l}\text { mRNA catabolism, regulation of } \\
\text { transcription from RNA polymerase II } \\
\text { promoter }\end{array}$ & $\begin{array}{l}\text { CCR4-NOT transcriptional complex, also } \\
\text { component of the major cytoplasmic } \\
\text { deadenylase }\end{array}$ \\
\hline YLR418C & $C D C 73$ & $\begin{array}{l}\text { RNA elongation from RNA polymerase } \\
\text { II promoter }\end{array}$ & $\begin{array}{l}\text { Constituent of Paf1 complex with RNA polymerase } \\
\text { II, Paf1, Hpr1, Ctr9, Leo1, Rtf1, and Ccr4 }\end{array}$ \\
\hline YER64W & CHD1 & $\begin{array}{l}\text { RNA elongation from RNA polymerase } \\
\text { II promoter }\end{array}$ & $\begin{array}{l}\text { Transcription elongation, nucleosome } \\
\text { remodeling, part of SAGA }\end{array}$ \\
\hline YOR061w & $C K A 2$ & $\begin{array}{l}\text { Regulation of transcription from RNA } \\
\text { polymerase II promoter }\end{array}$ & $\begin{array}{l}\text { Catalytic subunit of casein kinase } 2 \\
\text { phosphorylates Pta1 and RNAPII }\end{array}$ \\
\hline YKL139W & CTK1 & $\begin{array}{l}\text { Regulation of transcription from RNA } \\
\text { polymerase II promoter }\end{array}$ & $\begin{array}{l}\text { Phosphorylates Ser } 2 \text { of CTD, affects transcription } \\
\text { and pre-mRNA } 3^{\prime} \text {-end processing }\end{array}$ \\
\hline YDR069C & DOA4 & Protein deubiquitination & $\begin{array}{l}\text { Required for recycling ubiquitin from } \\
\text { proteasome-bound ubiquitinated intermediates }\end{array}$ \\
\hline YGL043W & DST1 & $\begin{array}{l}\text { RNA elongation from RNA polymerase } \\
\text { II promoter }\end{array}$ & $\begin{array}{l}\text { Elongation factor TFIIS, stimulates cleavage of } \\
\text { nascent transcripts stalled at transcription } \\
\text { arrest sites }\end{array}$ \\
\hline YHL030W & ECM29 & Protein catabolism & $\begin{array}{l}\text { Tethers proteasome core particle to the } \\
\text { regulatory particle }\end{array}$ \\
\hline YGR200C & ELP2 & $\begin{array}{l}\text { Regulation of transcription from RNA } \\
\text { polymerase II promoter }\end{array}$ & $\begin{array}{l}\text { Part of RNAPII Elongator histone } \\
\text { acetyltransferase }\end{array}$ \\
\hline YPL086C & ELP3 & $\begin{array}{l}\text { Regulation of transcription from RNA } \\
\text { polymerase II promoter }\end{array}$ & $\begin{array}{l}\text { Part of RNAPII Elongator histone } \\
\text { acetyltransferase }\end{array}$ \\
\hline YER032W & FIR1 & mRNA polyadenylylation & $\begin{array}{l}\text { Involved in } 3^{\prime} \text {-mRNA processing, interacts } \\
\text { with Ref2 }\end{array}$ \\
\hline YCL011C & $G B P 2$ & RNA export from nucleus & Poly $(A)^{+}$RNA-binding protein \\
\hline YGR252W & GCN5 & Chromatin modification & $\begin{array}{l}\text { Catalytic subunit of SAGA histone } \\
\text { acetyltransferase complex }\end{array}$ \\
\hline YNL199C & GCR2 & $\begin{array}{l}\text { Positive regulation of transcription from } \\
\text { RNA polymerase II promoter }\end{array}$ & $\begin{array}{l}\text { Transcriptional activator, interacts with } \\
\text { DNA-binding protein Gcr1 }\end{array}$ \\
\hline YMR255W & GFD1 & RNA export from nucleus & High-copy suppressor of $d b p 5$ mutation \\
\hline YBR034C & HMT1 & RNA export from nucleus & $\begin{array}{l}\text { Arginine methylation of hnRNPs, including } \\
\mathrm{Npl} 3 \text { and } \mathrm{Hrp} 1\end{array}$ \\
\hline YNL004W & HRB1 & RNA export from nucleus & $\begin{array}{l}\text { Poly }(\mathrm{A})^{+} \text {RNA-binding protein; similar to } \\
\text { Gbp2 and } \mathrm{Npl} 3\end{array}$ \\
\hline YLR384C & $I K I 3$ & $\begin{array}{l}\text { Regulation of transcription from RNA } \\
\text { polymerase II promoter }\end{array}$ & $\begin{array}{l}\text { Part of RNAPII Elongator histone } \\
\text { acetyltransferase }\end{array}$ \\
\hline YGL016W & KAP122 & Nucleocytoplasmic transport & $\begin{array}{l}\text { Karyopherin } \beta \text {, binds to nucleoporins Nup1 and } \\
\text { Nup2, synthetic lethal with gcr1 mutation }\end{array}$ \\
\hline YER110C & KAP123 & Nucleocytoplasmic transport & $\begin{array}{l}\text { Karyopherin } \beta \text {; conditional loss of Pse } 1 \text { in } \\
\text { kap123 mutant cells blocks mRNA export }\end{array}$ \\
\hline
\end{tabular}


TABLE 1. Continued

\begin{tabular}{|c|c|c|c|}
\hline Gene ID & Name & Biological process (GO terms) & Description \\
\hline YOR123C & LEO1 & $\begin{array}{l}\text { RNA elongation from RNA polymerase } \\
\text { II promoter }\end{array}$ & $\begin{array}{l}\text { Component of the Paf1 complex, histone } \\
\text { methylation; loss affects CTD } \\
\text { phosphorylation at Ser2 }\end{array}$ \\
\hline YDL051W & LHP1 & tRNA processing & La homolog \\
\hline YHR081W & $L R P 1$ & mRNA catabolism & Nuclear exosome \\
\hline YHR121W & LSM12 & RNA metabolism & $\begin{array}{l}\text { Interacts with Pbp1 and Pbp4 with likely role } \\
\text { in RNA processing }\end{array}$ \\
\hline YML062C & MFT1 & RNA export from nucleus & THO comlex subunit \\
\hline YHR015W & MIP6 & RNA export from nucleus & $\begin{array}{l}\text { Putative RNA-binding protein, interacts with } \\
\text { Mex67 }\end{array}$ \\
\hline YKP095W & MLP1 & mRNA export from nucleus & $\begin{array}{l}\text { Involved with Pml } 1 \text { and } \mathrm{Pml} 39 \text { in nuclear } \\
\text { retention of unspliced mRNAs }\end{array}$ \\
\hline YIL149C & $M L P 2$ & RNA export from nucleus & Nuclear retention of unspliced mRNA \\
\hline YKL074C & MUD2 & $\begin{array}{l}\text { U2-type nuclear mRNA branch site } \\
\text { recognition }\end{array}$ & $\begin{array}{l}\text { Similar to metazoan splicing factor U2AF65, } \\
\text { synthetic rescue of sub2 mutant }\end{array}$ \\
\hline YGR232W & NAS6 & Proteolysis & Non-ATPase subunit of the $26 \mathrm{~S}$ proteasome \\
\hline YKL068W & NUP100 & RNA export from nucleus & $\begin{array}{l}\text { GLFG motif-type nucleoporin, interacts } \\
\text { with Mex67 }\end{array}$ \\
\hline YBL079W & NUP170 & RNA export from nucleus & Nucleoporin, synthetic lethal with gcr1/2 \\
\hline YML103C & NUP188 & RNA export from nucleus & Nucleoporin, synthetic lethal with $g c r 1 / 2$ \\
\hline YMR153W & NUP53 & RNA export from nucleus & Nucleoporin, synthetic lethal with $g c r 1 / 2$ \\
\hline YGL094C & PAN2 & mRNA 3 '-end processing & Poly(A) nuclease subunit \\
\hline YKL025C & PAN3 & mRNA 3'-end processing & Poly(A) nuclease subunit \\
\hline YGR178C & PBP1 & mRNA polyadenylylation & Poly(A)-binding protein binding protein \\
\hline YMR129W & POM152 & RNA export from nucleus & $\begin{array}{l}\text { Nuclear pore membrane glycoprotein, } \\
\text { synthetic lethal with gcr } 1 / 2\end{array}$ \\
\hline YLR018C & POM34 & Nucleocytoplasmic transport & $\begin{array}{l}\text { Integral membrane protein of the nuclear pore, } \\
\text { synthetic lethal with } g_{c r} 1 / 2\end{array}$ \\
\hline YGR135W & PRE9 & Ubiquitin-dependent protein catabolism & The only nonessential $20 \mathrm{~S}$ proteasome subunit \\
\hline YEL037C & RAD23 & Negative regulation of protein catabolism & $\begin{array}{l}\text { Protein with ubiquitin-like } \mathrm{N} \text { terminus, binds } \\
\text { damaged DNA }\end{array}$ \\
\hline YDR195W & REF2 & mRNA processing & $\begin{array}{l}\text { Subunit of the APT subcomplex, involved } \\
\text { in the pre-mRNA } 3^{\prime} \text {-end cleavage }\end{array}$ \\
\hline YGL244W & RFT1 & Oligosaccharide transport & Loss affects CTD phosphorylation at Ser2 \\
\hline YHR200W & RPN10 & Ubiquitin-dependent protein catabolism & $\begin{array}{l}\text { Non-ATPase base subunit of the } 19 S \text { regulatory } \\
\text { particle (RP) of the } 26 \mathrm{~S} \text { proteasome }\end{array}$ \\
\hline YLR421C & RPN13 & Ubiquitin-dependent protein catabolism & $\begin{array}{l}\text { Subunit of the } 19 S \text { regulatory particle of } 26 S \\
\text { proteasome lid }\end{array}$ \\
\hline YOR001W & $R R P 6$ & mRNA catabolism & Nuclear exosome \\
\hline YDR159W & $S A C 3$ & RNA export from nucleus & $\begin{array}{l}\text { NPC-associated protein, part of } \\
\text { Sac3-Thp1-Sus1-Cdc31 complex }\end{array}$ \\
\hline YML013W & SEL1 & $\begin{array}{l}\text { Proteasomal ubiquitin-dependent protein } \\
\text { catabolism }\end{array}$ & $\begin{array}{l}\text { UBX domain-containing protein, interacts } \\
\text { with Cdc48 }\end{array}$ \\
\hline YBL058W & SHP1 & $\begin{array}{l}\text { Proteasomal ubiquitin-dependent protein } \\
\text { catabolism }\end{array}$ & $\begin{array}{l}\text { UBX domain-containing protein that } \\
\text { regulates Glc7 phosphatase activity } \\
\text { and interacts with Cdc } 48\end{array}$ \\
\hline YMR216C & SKY1 & Nucleocytoplasmic transport & NPL3 kinase \\
\hline YBR172C & SMY2 & Cytoskeleton organization and biogenesis & $\begin{array}{l}\text { Homolog of pombe Mpd2 (multicopy } \\
\text { suppressor of Ptr1/Tom1) }\end{array}$ \\
\hline YOL148C & SPT20 & Chromatin modification & SAGA subunit, required for its integrity \\
\hline YIL030C & SSM4 & ER-associated protein catabolism & $\begin{array}{l}\text { Ub ligase; ssm } 4 \text { mutation suppresses mRNA } \\
\text { instability caused by an rna14 mutation }\end{array}$ \\
\hline YBR11W-A & SUS1 & mRNA export from nucleus & $\begin{array}{l}\text { Part of Sac3-Thp1-Sus1-Cdc31 complex; component } \\
\text { of the SAGA histone acetylase complex }\end{array}$ \\
\hline YOR179C & SYC1 & $\begin{array}{l}\text { Transcription termination from } \\
\text { Pol II promoter }\end{array}$ & $\begin{array}{l}\text { Subunit of APT subcomplex of cleavage and } \\
\text { polyadenylation factor; role in } 3^{\prime} \text {-end formation of } \\
\text { polyadenylated and non-polyadenylated RNAs }\end{array}$ \\
\hline YNL253W & TEX1 & RNA export from nucleus & Component of THO/TREX complex \\
\hline YNL139C & THO2/RLR1 & mRNA export from nucleus & Component of THO/TREX complex \\
\hline
\end{tabular}




\begin{tabular}{|c|c|c|c|}
\hline Gene ID & Name & Biological process (GO terms) & Description \\
\hline YOL072W & THP1 & RNA export from nucleus & $\begin{array}{l}\text { NPC-associated protein, part of } \\
\text { Sac3-Thp1-Sus1-Cdc31 complex }\end{array}$ \\
\hline YBR082C & UBC4 & $\begin{array}{l}\text { Protein monoubiquitination, } \\
\text { protein polyubiquitination }\end{array}$ & $\begin{array}{l}\text { Ubiquitin-conjugating enzyme, interacts with } \\
\text { many SCF ubiquitin protein ligases }\end{array}$ \\
\hline YDR059C & UBC5 & Protein polyubiquitination & Ubiquitin-conjugating enzyme \\
\hline YFR010W & UBP6 & Protein deubiquitination & $\begin{array}{l}\text { Ubiquitin-specific protease in the base } \\
\text { subcomplex of } 265 \text { proteasome }\end{array}$ \\
\hline YGR184C & UBR1 & $\begin{array}{l}\text { Protein monoubiquitination, protein } \\
\text { polyubiquitination }\end{array}$ & Ubiquitin-protein ligase (E3) \\
\hline YBR173C & UMP1 & Proteasome assembly & $\begin{array}{l}\text { Chaperone required for correct maturation } \\
\text { of the } 20 \mathrm{~S} \text { proteasome }\end{array}$ \\
\hline YGL227W & VID30 & $\begin{array}{l}\text { Proteasomal ubiquitin-dependent } \\
\text { protein catabolism }\end{array}$ & $\begin{array}{l}\text { Involved in proteasome-dependent } \\
\text { catabolite degradation of FBPase }\end{array}$ \\
\hline YKL214C & YRA2 & RNA export from nucleus & mRNA export adaptor, redundant with Yra1 \\
\hline YMR273C & ZDS1 & RNA export from nucleus & $\begin{array}{l}\text { ceg1-ts suppressor, implicated in mRNA } \\
\text { nuclear export, } \mathrm{Y} 2 \mathrm{H} \text { interaction with Dbp5 }\end{array}$ \\
\hline YNL016W & PUB1 & mRNA catabolism & $\begin{array}{l}\text { Poly }(A)^{+} \text {RNA-binding protein, required } \\
\text { for stability of many mRNAs }\end{array}$ \\
\hline YOR304W & ISW2 & Chromatin remodeling & $\begin{array}{l}\text { Member of the imitation-switch (ISWI) } \\
\text { class of ATP-dependent chromatin } \\
\text { remodeling complexes }\end{array}$ \\
\hline YLR095C & $1 O C 2$ & Chromatin remodeling & $\begin{array}{l}\text { Member of an Isw1b complex with } \\
\text { nucleosome-stimulated ATPase activity }\end{array}$ \\
\hline YFR013W & $1 O C 3$ & Chromatin remodeling & $\begin{array}{l}\text { Member of an Isw1a complex with } \\
\text { nucleosome-stimulated ATPase activity }\end{array}$ \\
\hline
\end{tabular}

the transcription-site-proximal GFP-RZ mRNP pool, which is visualized by FISH as an exaggerated and/or fragmented dot. Importantly, this effect is specific, since other mutants that affect poly $(\mathrm{A})^{+}$mRNA export to a comparable or greater extent (e.g., $\operatorname{lrp} 1 \Delta$ ) (Hieronymus et al. 2004; data not shown) had no effect on dot morphology.

\section{The Sac3-Thp1-Sus1-Cdc31 complex impacts the dot-gene tether}

To further explore the role of the Sac3-Thp1-Sus1-Cdc31 complex in the tethering of the mRNA dot to its cognate gene during transcription as well as after the transcriptional shutoff, we simultaneously monitored the locations of the dots with FISH and the reporter locus with the TetR-GFP/ $\mathrm{TetO}_{448}$ system as described above. As previously reported, the dot as well as its tether to the reporter gene persist for at least $60 \mathrm{~min}$ after transcriptional shutoff in WT cells (Abruzzi et al. 2006). In the sus $1 \Delta$, sac3s, and thp $1 \Delta$ mutant strains, however, we observed that the GAL-GFP-RZ dots progressively detach from their loci of origin after transcriptional shutoff (Fig. 2). To extend this observation, we also tested the GAL-GFP-pA reporter construct integrated at the same genomic location. GAL-GFP-pA construct possesses a normal GAL1 3'-UTR and polyadenylation signal (while its GFP chromophore has been inactivated to enable visualization of TetR-GFP/TetO ${ }_{448}$ ), and the GAL-GFP-pA dot appears normal during active transcription (Fig. 1I). How- ever, it similarly detaches from its gene in the three deletion strains after transcriptional shutoff (Fig. 2). These data indicate that the Sac3-Thp1-Sus1-Cdc31 complex contributes to retention of a post-transcriptional dot near its gene of origin. Moreover, the lack of an effect before transcriptional shutoff suggests that there are additional, Sac3-, Thp1-, and Sus1-independent mechanisms contributing to the dot-gene tether during active transcription.

\section{The Sac3-Thp1-Sus1-Cdc31 complex also impacts the gene-nuclear periphery tether}

The difference in dot phenotype between GAL-GFP-pA and GAL-GFP-RZ in the mutant strains (Fig. 1) parallels a difference in dot-gene dissociation kinetics, as the GALGFP-RZ mRNA dot separates more quickly from the gene after transcriptional shutoff (Fig. 2C). Moreover, differences in dot phenotypes were previously observed in wildtype cells: the GAL-GFP-pA dots disappear more quickly than the GAL-GFP-RZ dots after transcriptional shutoff, which further correlates with differences in the dissociation of the two genes from the nuclear rim after transcriptional shutoff in WT cells: GAL-GFP-pA dot dissociates more quickly than the GAL-GFP-RZ dot (Abruzzi et al. 2006). These differences presumably reflect the different RNP compositions of the two transcripts (see Discussion).

Motivated by these observations, we examined the relationship of the reporter loci to the nuclear periphery 

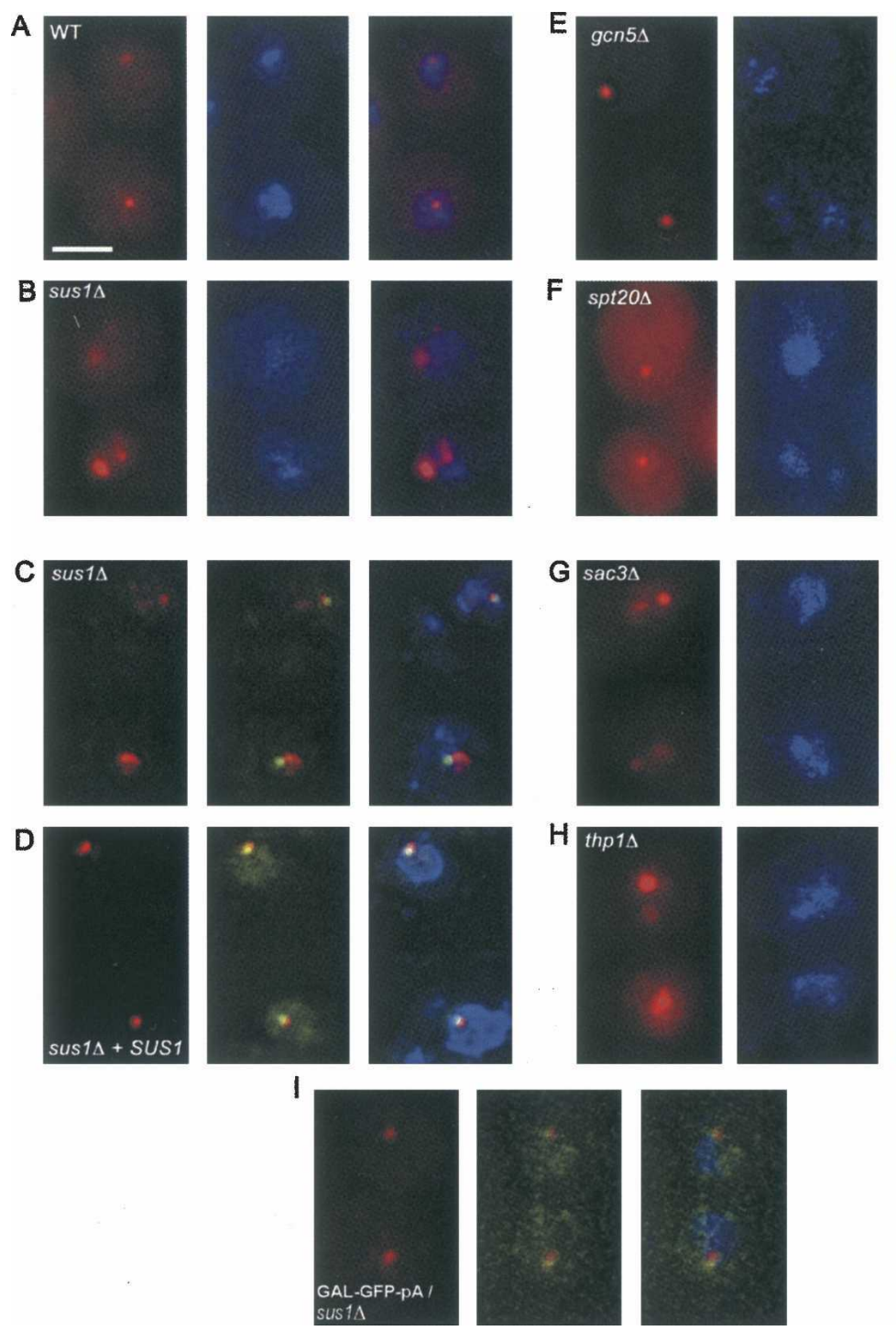

FIGURE 1. Altered nuclear-retained $(A, B, E, F)$ TDH-GFP-RZ and $(C, D)$ GAL-GFP-RZ

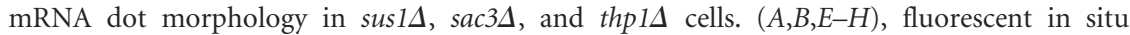
hybridization (FISH) for the TDH-GFP-RZ mRNA in (A) wild-type (WT), (B) sus1 1 , (E) $g c n 5 \Delta,(F) \operatorname{spt} 20 \Delta,(G) s a c 3 \Delta$, and $(H)$ thp $1 \Delta$ cells. (Left panels) FISH signal (red); (middle panels) DAPI staining for total DNA (blue); (right panels) overlay. Scale bar, $2 \mu \mathrm{m} .(C, D)$ FISH for the GAL-GFP-RZ mRNA with simultaneous visualization of the $\mathrm{TetO}_{448}$ array integrated at the BMH1 locus on Chromosome V, $<5 \mathrm{~kb}$ away, using TetR-GFP in $(C)$ sus $1 \Delta$ cells and $(D)$ sus $1 \Delta$ cells expressing an ectopically integrated WT copy of SUS1 as well as a Nup49-GFP (the presence of Nup49-GFP has no effect on the dot morphology phenotype). (Left panels) FISH signal (red); (middle panels) FISH signal (red) overlaid on TetR-GFP signal (green); (right panels) triple overlay of FISH signal, TetR-GFP signal, and DAPI staining for the total DNA (blue). (I) In contrast to the GAL-GFP-RZ mRNA dot $(C, D)$, no enlargement of the GAL-GFP-pA mRNA dot is observed in sus1s cells.

during active transcription in the sus $1 \Delta$, sac $3 \Delta$, and thp $1 \Delta$ strains as well as peripheral retention after transcriptional shutoff. In contrast to WT cells (Abruzzi et al. 2006), the GAL-GFP-pA gene locus completely failed to localize to the nuclear rim under activating conditions in the deletion strains (galactose) (Fig. 3A). This recapitulates perfectly the behavior of the endogenous GAL1 locus in these strains
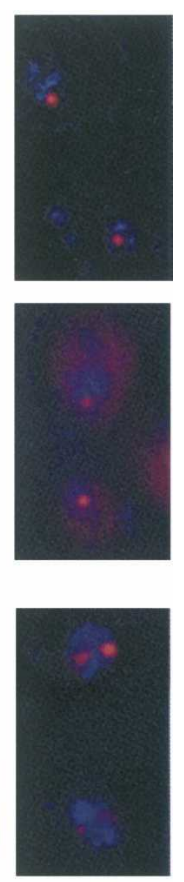

(Cabal et al. 2006; Drubin et al. 2006). In contrast, the GAL-GFP-RZ gene still localized to the nuclear periphery in the deletion strains. However, its association was rapidly lost upon transcriptional shutoff, with kinetics that paralleled that of RNAP II runoff (Fig. 3B). This contrasts with WT cells, in which the GAL$G F P-R Z$ locus dissociates from the nuclear rim only very slowly after glucose addition (>60 min) (Abruzzi et al. 2006). The results suggest the existence of additional transcription-dependent tether(s) that maintain an actively transcribing GAL-GFP-RZ locus at the nuclear periphery. They also suggest that the post-transcriptional retention of the GAL-GFP-RZ locus at the nuclear periphery requires the Sac3-Thp1-Sus1Cdc31 complex.

Because Sus1 directly participates in transcription from the GAL1 promoter (Rodriguez-Navarro et al. 2004; Kohler et al. 2006), we addressed the possibility that the differences in intranuclear positioning between the active GAL-GFP-pA and GAL-GFP-RZ genes in the sus $1 \Delta$ mutant is a consequence of differential transcriptional effects on these two genes. To this end, we compared the RNAP II occupancy on these two reporter constructs, using chromatin immunoprecipitation (ChIP). The magnitude of reduction in RNAP II occupancy of GAL-GFP-RZ and GAL-GFP-pA in sus1s relative to WT cells was identical (Fig. 3C), and it was also identical to that of the endogenous GAL1 gene in sus1D cells (data not shown). Moreover, the decrease was quantitatively mirrored by the steady-state mRNA level differences of both reporter genes between the two strains (Fig. 3D).

We also found that a loss of Gcn5, which associates with the GAL1 promoter (Dhasarathy and Kladde 2005) and impacts its transcriptional activity comparably to sus1s (approximately threefold) (Fig. 3C,D; Dudley et al. 1999), had no effect on peripheral retention of the GAL-GFP-pA gene (Fig. 3A). Moreover, it had no more than a modest effect on the dissociation kinetics of the GAL-GFP-RZ locus from the nuclear rim (Fig. 3B). We conclude that the differential impact of an Sus1 deletion on the morphology of GAL-GFP$\mathrm{RZ}$ and GAL-GFP-pA mRNA dots as well as on the nuclear 


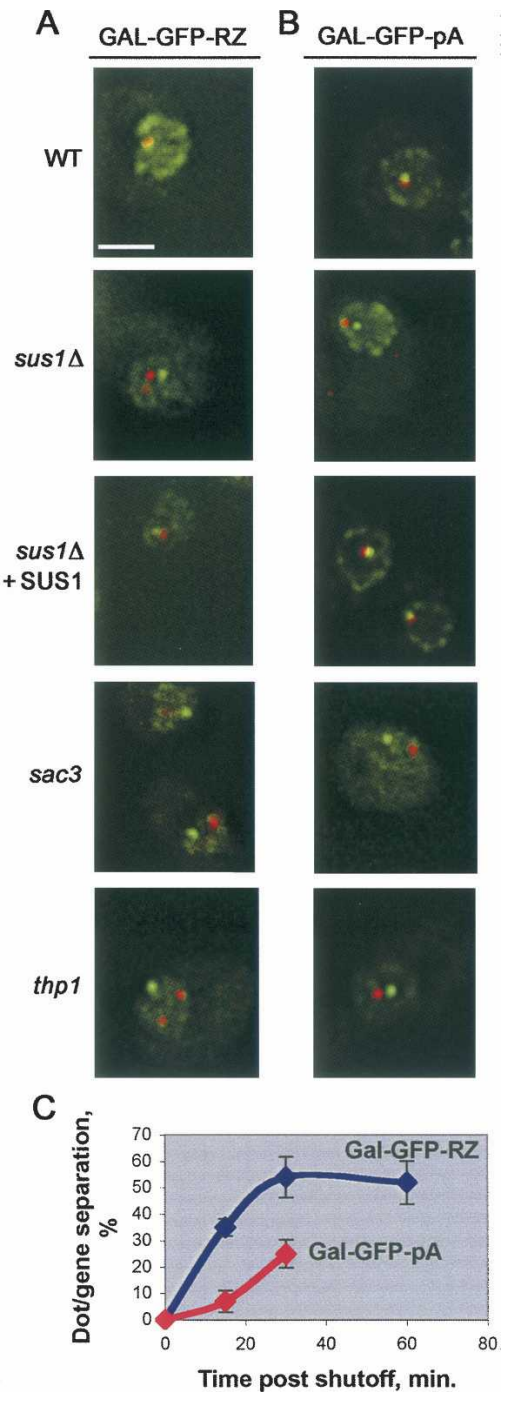

FIGURE 2. Deletions of SUS1, SAC3, and THP1 lead to a loss of association of GAL-GFP-RZ and GAL-GFP-pA mRNA dots with their respective genes. (A) GAL-GFP-RZ mRNA or (B) GAL-GFP-pA mRNA is visualized by FISH (red); respective reporter loci are visualized using the TetR-GFP/TetO ${ }_{448}$ system (green); and nuclear periphery is visualized using Nup49-GFP (green). Images are taken at the 30-min time point after the transcriptional shutoff. Scale bar, $2 \mu \mathrm{m}$. (C) relative kinetics of the GAL-GFP-RZ and GAL-GFP-pA mRNA dots' separation from respective genes after transcriptional shutoff in sus $1 \Delta$ cells. (Very few GAL-GFP-pA mRNA dots remain at $60 \mathrm{~min}$ in sus1s cells; dot/locus separation in WT never exceeded 5\%.) Error bars represent standard deviation.

rim association of these genes is not due to its SAGA-related functions but to the Sac3-Thp1-Sus1-Cdc31 complex. We also speculate that post-transcriptional mRNP may more generally facilitate gene repositioning to the nuclear periphery.

\section{DISCUSSION}

Using a FISH-based genetic screen, we identified Susl, Thp1, and Sac3 as factors that have an impact on mRNA dot morphology. They also affect the persistent tethering of dots to their cognate genes as well as to the nuclear rim after transcriptional shutoff. These findings reveal a novel, post-transcriptional function of the Sac3-Thp1-Sus1-Cdc31 complex in addition to its previously described roles in transcription itself, mRNA export, and the tethering of genes to the nuclear periphery during active transcription. Indeed, it is striking that the disruption of this complex affects the tethering of post-transcriptional mRNPs to their respective genes as well as the capture and retention of transcriptionally activated loci at the nuclear rim. Although we cannot rule out indirect effects, a parsimonious interpretation of this unexpected dual role is that the dot-togene and gene-to-nuclear periphery interactions are both mediated by post-transcriptional mRNP decorated with the Sac3-Thp1-Sus1-Cdc31 complex. Although the steady-state distribution of these proteins is predominantly at the nuclear rim, this does not preclude an association with mRNP. Indeed, Sus1 and its partners interact with mRNA and chromatin, in addition to their interactions with the nuclear pores (Fischer et al. 2002; Gallardo et al. 2003; Lei et al. 2003; Rodriguez-Navarro et al. 2004; Kohler et al. 2006).

Characterization of the sus $1 \Delta$, thp $1 \Delta$, and sac $3 \Delta$ strains indicates that fragmentation of the GAL-GFP-RZ mRNP dot is intimately related to weakening of the gene-dot tethering. This might indicate that dot integrity is dependent on contacts between dot mRNP, Sac3-Thp1Sus1-Cdc31 complex, and chromatin. When these are diminished (e.g., in sus $1 \Delta$ ), dot fragmentation as well as separation of the dot and the gene occur (Figs. 1, 4). Notably, despite their fragmentation in the mutant backgrounds, the GAL-GFP-RZ dots do not completely disperse and disappear, indicating that there must be Sus1-, Sac3-, and Thp1-independent associations between the individual mRNP particles within the dot that contribute to its integrity.

We find that deletions of Sus1, Sac3, and Thp1 affect the dot-gene interactions not only in the case of the $3^{\prime}$-endimpaired GFP-RZ construct, but also in the case of the GAL-GFP-pA mRNP, suggesting that Sus1, Sac3, and Thp1 are also components of the GAL-GFP-pA-containing dots. Moreover, sus $1 \Delta$, sac3s, and thp1s mutations strongly impact the association of the GAL-GFP-pA gene with the nuclear rim. Yet their effects on this reporter differ in two respects from their effects on GAL-GFP-RZ: the GAL-GFP$\mathrm{pA}$ dots are neither enlarged nor fragmented in the mutants, and the association of the GAL-GFP-pA gene with the nuclear periphery is abolished completely, i.e., even during active transcription. As only the GAL-GFP-RZ gene remains associated with the nuclear rim during active transcription in the mutant strains, there must be additional transcription-dependent contacts that are stronger or more numerous between the GAL-GFP-RZ gene and the nuclear periphery. 
A

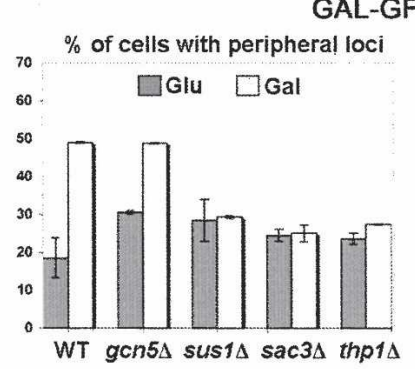

B

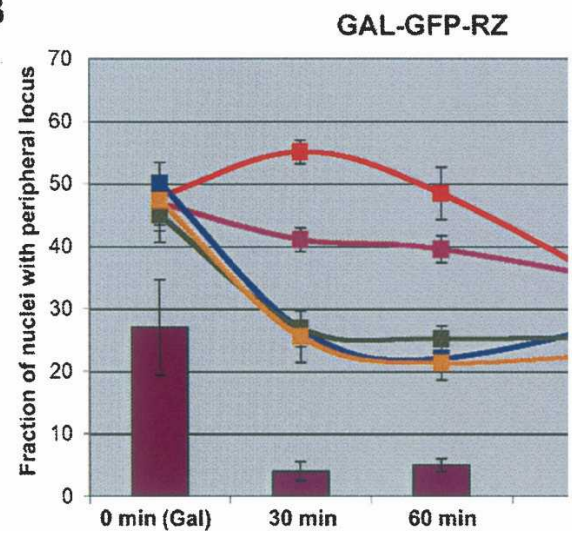

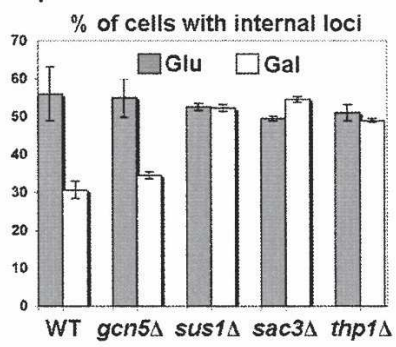

C

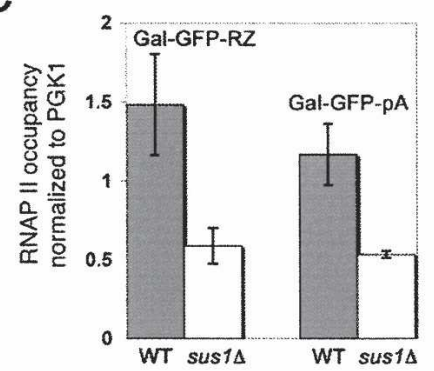

D

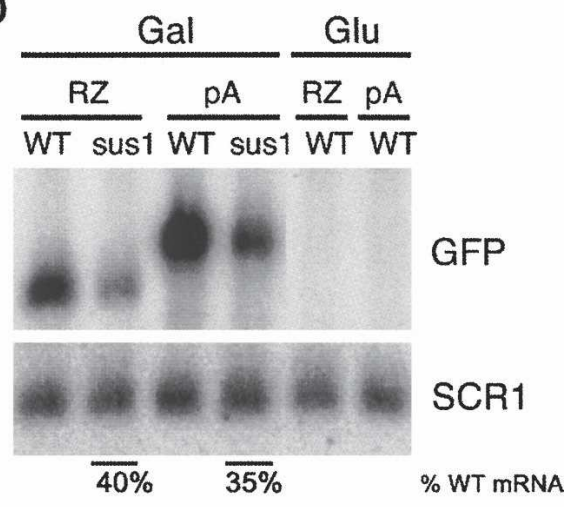

FIGURE 3. Deleting SUS1, SAC3, and THP1 has distinct transcription-independent effects on retention of the activated GAL-GFP-pA and GAL-

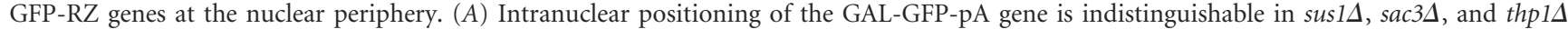
cells under activating and repressing conditions. The proportion of cells with (left panel) peripherally and (right panel) internally positioned loci is plotted for galactose-grown $(\mathrm{Gal})$ and glucose-grown $(\mathrm{Glu})$ cells. The intranuclear position of the locus was revealed using the TetR-GFP/TetO ${ }_{448}$ system. The nuclear periphery was visualized using Nup49-GFP fusion coexpressed in the same strain. Subperipheral fraction remains unchanged at $\sim 20 \%$ (data not shown). Error bars represent standard deviation. (B) Dissociation of the GAL-GFP-RZ gene locus from the nuclear periphery in sus $1 \Delta$, sac $3 \Delta$, and thp $1 \Delta$ cells is dramatically accelerated and parallels the kinetics of the RNAP II runoff from the gene. The proportion of cells with a peripherally positioned GAL-GFP-RZ gene locus after 0,30 , or $60 \mathrm{~min}$ of transcriptional shutoff or in steady-state glucose conditions is plotted. For comparison, RNAP II occupancy after transcriptional shutoff as well as in steady-state glucose conditions, measured by ChIP, is shown as vertical bars. Error bars represent standard deviation. (C) RNAP II occupancy of the GAL-GFP-pA and GAL-GFP-RZ reporter constructs in sus $1 \Delta$ cells is affected to the same extent. The RNAP II levels are normalized to the RNAP II occupancy on the endogenous PGK1 gene, which is unaffected by the loss of SUS1. Error bars represent standard deviation. (D) Northern blot quantification of the steady-state GALGFP-pA and GAL-GFP-RZ mRNA levels using a GFP-specific probe in WT and sus1s cells grown on galactose and glucose. (SCR1) Loading control used for normalization.

Although we cannot rule out that such differential contacts may be mediated by chromatin per se, there are no known chromatin effects associated with replacing the GAL1 3'-UTR with the ribozyme. An alternative (or additional) possibility would be due to a difference between GAL-GFP-pA and GAL-GFP-RZ mRNP structure or composition, which can be qualitative, quantitative, or both. Indeed, we reported previously that the GAL-GFP-RZ gene shows an altered cotranscriptional recruitment profile of Yral (Abruzzi et al. 2006). Moreover, a quantitative difference is indicated by the consistently larger GAL-GFPRZ dots than the GAL-GFP-pA dots (data not shown; D. Zenklusen and R. Singer, pers. comm.). Larger dots would provide more contact area between RZ mRNP and the nuclear periphery than between pA RNP and the periphery, which might contribute to $\mathrm{RZ}$ gene retention at the nuclear rim during active transcription even in a Sus1-deleted strain (Fig. 4).
This view implies that there are multiple contacts between a tethered gene and the NPC. Indeed, it has been shown that transcriptional activator binding (Schmid et al. 2006), transcription-associated chromatin remodeling (Brickner et al. 2007), and perhaps the act of transcription itself (Casolari et al. 2005; Cabal et al. 2006; Drubin et al. 2006) all contribute to the recruitment of the activated GAL genes to the nuclear periphery. Moreover, diminished perinuclear positioning during active transcription was observed for endogenous GAL genes in sus $1 \Delta$ and sac3 $\Delta$ cells (e.g., Cabal et al. 2006; Drubin et al. 2006). Our findings extend these conclusions by suggesting that this effect is mediated by the post-transcriptional mRNP and becomes relevant only after initial contact of the activated gene with the nuclear rim (modeled in Fig. 4). Whereas the initial encounter of the locus with the nuclear periphery is transcriptional activator-dependent, independent of Sus1 (Schmid et al. 2006), and precedes the onset of transcription 


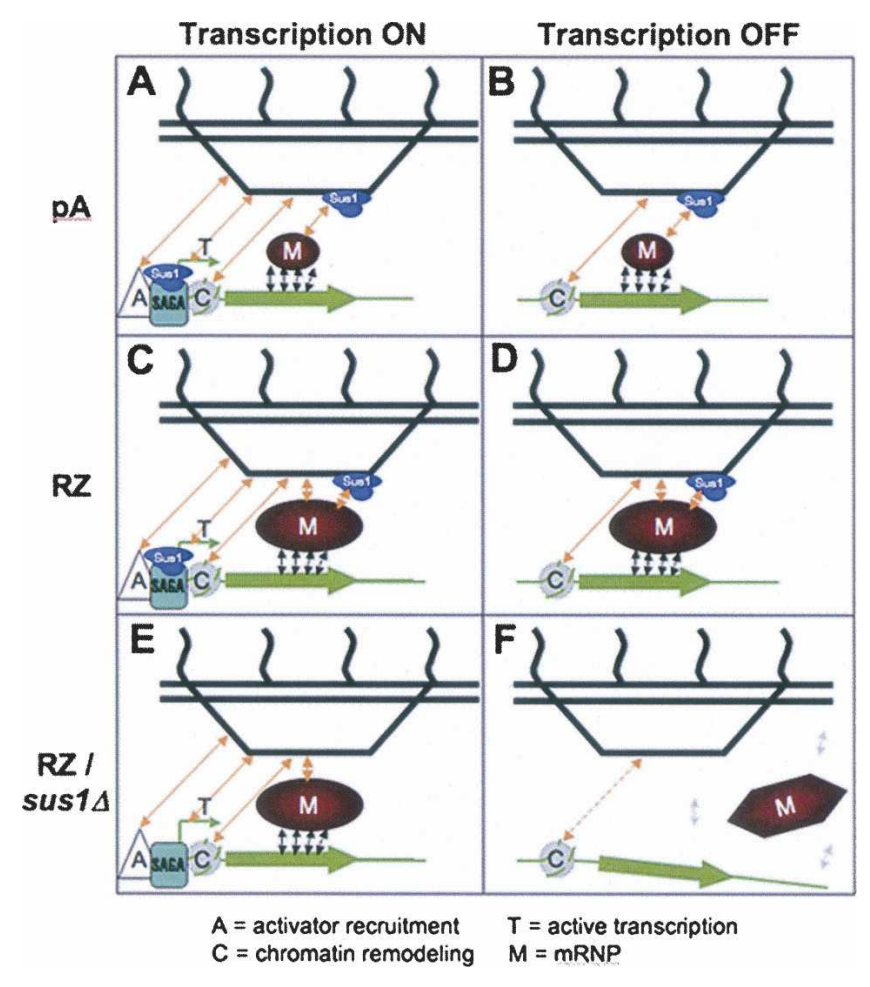

FIGURE 4. A model that integrates the multiple interactions between the activated GAL genes (green), non-nascent mRNP pools (red), and nuclear pores (black), emphasizing the dual role of the Sac3-Thp1Sus1-Cdc31 complex (blue) at the site of transcription as well as at the nuclear periphery. $(A)$ In WT cells, perinuclear repositioning of the GAL-GFP-pA locus occurs via a combined action of multiple mechanisms including transcriptional activator (A)-dependent recruitment as well as transcription (T)-, chromatin (C)-, and mRNP (M)-mediated capture and retention. (B) Upon shutoff of transcription, persistent chromatin- and mRNP-mediated retention prevents the immediate departure of the GAL-GFP-pA locus from the nuclear rim. (C) The abnormal and large GAL-GFP-RZ mRNP pool produced when mRNA $3^{\prime}$-end processing is bypassed by RZ makes additional contacts at the nuclear pore, which are not Sac3-Thp1Sus1-Cdc31 complex-dependent, and hence is strongly retained at the nuclear rim. (D) Upon transcriptional shutoff, the synergy of these additional contacts with the NPC, acting together with the Sac3-Thp1-Sus1-Cdc31 complex-dependent and chromatin-dependent contacts, allows the GAL-GFP-RZ mRNP to persist at the nuclear periphery longer than GAL-GFP-pA. (E) Even in the absence of the Sac3-Thp1-Sus1-Cdc31 complex at the NPC, the synergy of the activator-mediated contacts, ongoing transcription, chromatinmediated and the Sac3-Thp1-Sus1-Cdc31 complex-independent interactions of the exaggerated GAL-GFP-RZ mRNP with the NPC support a modest degree of peripheral tethering. $(F)$ Upon transcriptional shutoff, this modest tethering fails immediately, while the aberrant $\mathrm{mRNP}$ remodeling (illustrated by the change in shape of the mRNP pool) and/or compromised export of the GAL-GFP-RZ mRNP in the absence of Sac3-Thp1-Sus1-Cdc31 complex causes its separation from the gene.

(Brickner et al. 2007), stable retention becomes independent of active transcription and is facilitated by the Sac3-Thp1Sus1-Cdc31 complex; it is more generally aided by intrinsic properties of post-transcriptional mRNP. We suggest that multiple tethering mechanisms serve to strengthen the association between the active gene and NPC and hence facili- tate rapid mRNA export, as originally proposed by Blobel in the gene gating hypothesis (Blobel 1985).

\section{MATERIALS AND METHODS}

\section{Strain design and growth conditions}

Construction of strains bearing the TDH-GFP-RZ reporter loci marked with nourseothricin resistance and KanMX-marked deletions of selected nonessential genes was done using the approach originally developed for genome-wide scoring of synthetic lethal interactions (Tong et al. 2001). Reporter strains designed for mating with deletion array strains were in a Y7092 background

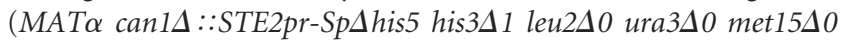
lyp1s trp1S::GAL1-IpgB1-URA3) (Alto et al. 2006; gift from Charlie Boone).

Yeast strains other than the ones used in the FISH-based screen for altered dot morphology as well as their derivation are described in detail in Table 2. To delete the SUS1, SAC3, and $T H P 1$, the kanamycin (KanMX) cassette plus respective flanking regions were PCR-amplified from the respective KanMXmarked deletion strains in the BY4741 background (MATa

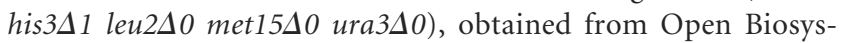
tems. The fragment encompassing NUP49-GFP fusion and HIS3 (Huh et al. 2003) was amplified from the Invitrogen strain collection. Integrations were verified by PCR and/or Southern blotting.

Yeast cell growth conditions for FISH, visualization of GFP fusion proteins, as well as for galactose-to-glucose shifts were as described (Abruzzi et al. 2006).

\section{Plasmid constructs and oligonucleotide primers}

The primers used in this study are listed in Table 3. Plasmid pDB700 was designed for integrating the TDH3-GFP-RZ reporter marked by nureseothricin resistance marker gene NatMX (Goldstein and McCusker 1999) into the genomic trp1 locus. To this end, NatMX was amplified with oDB1082/1083 and cloned into the AatII site of the pRS304/2 $\mu$ bearing TDH3-GFP-RZ (Dower et al. 2004), thus replacing its $2 \mu$ origin of replication. Integration was conducted after linearization at the Bsu36I site within the TRP1 gene sequence.

pDB716 and pDB719 (described in Abruzzi et al. 2006) were designed for inserting the GAL-GFP-RZ and GAL-GFP-pA, respectively, by the gamma-integration method (Sikorski and Hieter 1989) into the intergenic region between ECM32 and $B M H 1$, after linearization with NotI and selecting for $\operatorname{Trp}^{+}$ transformants.

To generate pDB729, WT genomic SUS1 fragment was amplified by PCR with oDB1152 and oDB1153, cloned into the Not site of pDB700, followed by releasing the TDH-GFP-RZ reporter from the polylinker after digesting with SpeI + ApaI, repairing the ends with T4 DNA polymerase, and religating. Integration was conducted into TRP1 locus after linearization with Bsu36I, with selection for nurseothricin resistance.

\section{Microscopy}

GFP fusion proteins were observed in cells grown to $\mathrm{OD} \sim 0.5$ and fixed for $15 \mathrm{~min}$ in $4 \%$ paraformaldehyde (without acetic 
TABLE 2. Yeast strains other than the deletion sublibrary used in FISH-based screen

\begin{tabular}{|c|c|c|}
\hline Y7092 & 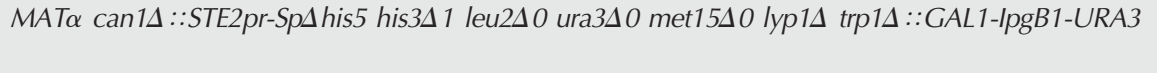 & $\begin{array}{l}\text { Tong and } \\
\text { Boone (2007) }\end{array}$ \\
\hline YDB526 & TDH-GFP-RZ reporter (pDB700) integrated into Y7092 & This study \\
\hline YDB527 & TDH-GFP-RZ (pDB700)::NatMX, sus1A::KanMX segregant of a cross with YDB526 & This study \\
\hline YDB528 & TDH-GFP-RZ (pDB700)::NatMX, sac3s ::KanMX segregant of a cross with YDB526 & This study \\
\hline YDB529 & TDH-GFP-RZ (pDB700)::NatMX, thp1s::KanMX segregant of a cross with YDB526 & This study \\
\hline YDB530 & TDH-GFP-RZ (pDB700)::NatMX, gcn5s ::KanMX segregant of a cross with YDB526 & This study \\
\hline YDB531 & TDH-GFP-RZ (pDB700)::NatMX, spt204::KanMX segregant of a cross with YDB526 & This study \\
\hline YDB532 & $\begin{array}{l}\text { MATa, ura3, trp1, his3, leu2::LEU2 tetR-GFP, 2x224tet0 URA3 integrated between } \\
\text { BMH1 and PDA1 }\end{array}$ & $\begin{array}{l}\text { AE3 in Abruzzi } \\
\text { et al. (2006) }\end{array}$ \\
\hline YDB533 & GAL-GFP-RZ (pDB716) + NUP49-GFP, HIS3 in YDB532 & This study \\
\hline YDB534 & GAL-GFP-pA (pDB719) + NUP49-GFP, HIS3 in YDB532 & This study \\
\hline YDB535 & sus1d::KanMX in YDB533 & This study \\
\hline YDB536 & sus1d::KanMX in YDB534 & This study \\
\hline YDB537 & $\operatorname{sac} 3 \Delta:: K a n M X$ in YDB533 & This study \\
\hline YDB538 & sac3s ::KanMX in YDB534 & This study \\
\hline YDB539 & thp1s::KanMX in YDB533 & This study \\
\hline YDB540 & thp1s::KanMX in YDB534 & This study \\
\hline YDB541 & WT SUS1 gene (pDB729) integrated into trp1 in YDB535 & This study \\
\hline YDB542 & WT SUS1 gene (pDB729) integrated into trp1 in YDB536 & This study \\
\hline
\end{tabular}

acid) using an Olympus IX70-based DeltaVision workstation (Applied Precision). Z-stacks were taken at $0.2 \mu \mathrm{m}$ step size and subjected to constrained iterative deconvolution. Positions of the TetR-GFP marked locus were scored in the z-section that cuts through the middle of the nucleus as described (Brickner and
Walter 2004) into intranuclear, peripheral, and subperipheral (i.e., locus touching the nuclear envelope but not coplanar with it). The subperipheral fraction varied little in all conditions and therefore is not reported in Figure 3. Each experiment was done in replicate, and between 100 and 150 cells were scored per sample per time

TABLE 3. Oligonucleotide primers

\begin{tabular}{|c|c|c|}
\hline Name & Sequence $\left(5^{\prime}\right.$ to $\left.3^{\prime}\right)$ & Purpose/notes \\
\hline oDB1082 & ACATGGAGGCCCAGAATACCC & Amplifying NatMX gene \\
\hline oDB1083 & CAGTATAGCGACCAGCATTCAC & Amplifying NatMX gene \\
\hline oDB1128 & CGTACTTGCCATCCCTTACG & Upstream of SUS1 for disruption \\
\hline oDB1129 & AAGGTGGGTAACGTGAATTAGG & Downstream from SUS1 for disruption \\
\hline oDB1130 & TGAAGGCTGTCTGACGTTGT & $\begin{array}{l}\text { Upstream of oDB1128 for checking } \\
\text { disruption junction }\end{array}$ \\
\hline oDB1146 & GGAGAGAGGAAAGCAGCAGA & Upstream of $S A C 3$ for disruption \\
\hline oDB1147 & GTATTTGCAACCCTGGCTTC & Downstream from $S A C 3$ for disruption \\
\hline oDB1148 & ATTCTCTCGCTGACCCAAGA & $\begin{array}{l}\text { Upstream of oDB1146 for checking } \\
\text { disruption junction }\end{array}$ \\
\hline oDB1149 & TGATCATGGCTAGCTTGGTG & Upstream of THP1 for disruption \\
\hline oDB1150 & TTGTAGCCTTGCAACGACAG & Upstream of THP1 for disruption \\
\hline oDB1151 & GGCAACTAAGGGAACCACAA & $\begin{array}{l}\text { Upstream of oDB1149 for checking } \\
\text { disruption junction }\end{array}$ \\
\hline oDB1152 & TTGAATTCAAGGAAAATGCCGAAAGAAT & Amplifying WT SUS1 for complementation \\
\hline oDB1153 & TTGAGCTCCAATTCATTCATTATGTTGTGGA & Amplifying WT SUS1 for complementation \\
\hline KA56 & GCCTTATTTCTGGGGTAATTAATCAGCGAAGCGATG & ChIP, 5'-UTR of GAL1 (forward) \\
\hline KA100 & AACTCCAGTGAAGAGTTCTTCTCCTTT & ChIP, within ORF of GFP (reverse) \\
\hline KD209 & GT*GCCCATTAACAT* CACCATCTAAT ${ }^{*}{ }^{*}$ CAACA AGAAT*TGGGACAACT $* C C A G T$ & FISH probe for GFP \\
\hline KD210 & GTACAT*AACCTTCGGGCAT*GGCACTCTT*GAAAAAGTCAT*GCCGTTTCAT*AT & FISH probe for GFP \\
\hline KD211 & GATTCCAT*TCTTTTGTT*TGTCTGCCAT*GATGTATACAT*TGTGTGAGTT*ATA & FISH probe for GFP \\
\hline KD212 & CCCAGCAGCT*GTTACAAACT*CAAGAAGGACCAT*GTGGTCT*CTCTTTTCGT*T & FISH probe for GFP \\
\hline KA480 & ACGGAAGAGCTGCTGAAAAA & $\begin{array}{l}\text { Amplification of NUP49-GFP, } \\
\text { HIS3 fragment }\end{array}$ \\
\hline KA481 & TTGAATTGGGGTAGGCTCAG & $\begin{array}{l}\text { Amplification of NUP49-GFP, } \\
\text { HIS3 fragment }\end{array}$ \\
\hline
\end{tabular}

(T*) Amino-modified dT. 
point in each replicate in all experiments shown. FISH with Cy3labeled oligonucleotide probes was carried out according to Dower et al. (2004). Red/green channel signal offset due to chromatic aberration alone, as estimated by imaging TetraSpec beads (100 nm diameter, Invitrogen/Molecular Probes) under identical conditions, was negligible compared to the separation of FISH (Cy3) and GFP signals.

\section{Chromatin immunoprecipitation and RNA analyses}

RNAP II ChIP was performed using monoclonal antibody 8WG16 (Covance). Target DNA levels in input and IP samples were determined by real-time PCR using RotorGene (Corbett Research), and results were normalized as described (Abruzzi et al. 2004). The Northern hybridization signals in Figure 3 obtained with a GFPspecific probe were normalized to respective signals for SCR1, a RNAP III transcript, using ImageQuant software. Signal ratios were identical to the ChIP signal ratios in the respective strains.

\section{ACKNOWLEDGMENTS}

We appreciate the technical assistance of Prabhat Mallik and Andrey Belostotsky. We are grateful to the Boone, Nasmyth, and Wente laboratories for strains, as well as to Kristine O'Brien, other members of the Melissa Moore laboratory, and Alexey Khodjakov for help with deconvolution microscopy. This work was supported in part by grants from NIH to D.A.B. and J.A.C. (\#GM073872) and to M.R. (\#GM23549) and from the NSF to D.A.B. (Grant MCB0424651).

Received August 9, 2007; accepted September 21, 2007.

\section{REFERENCES}

Abruzzi, K.C., Lacadie, S., and Rosbash, M. 2004. Biochemical analysis of TREX complex recruitment to intronless and intron-containing yeast genes. EMBO J. 23: 2620-2631.

Abruzzi, K.C., Belostotsky, D.A., Chekanova, J.A., Dower, K., and Rosbash, M. 2006. 3'-End formation signals modulate the association of genes with the nuclear periphery as well as mRNP dot formation. EMBO J. 25: 4253-4262.

Alto, N.M., Shao, F., Lazar, C.S., Brost, R.L., Chua, G., Mattoo, S., McMahon, S.A., Ghosh, P., Hughes, T.R., Boone, C., et al. 2006. Identification of a bacterial type III effector family with $\mathrm{G}$ protein mimicry functions. Cell 124: 133-145.

Basehoar, A.D., Zanton, S.J., and Pugh, B.F. 2004. Identification and distinct regulation of yeast TATA box-containing genes. Cell 116: 699-709.

Blobel, G. 1985. Gene gating: A hypothesis. Proc. Natl. Acad. Sci. 82: 8527-8529.

Brickner, J.H. and Walter, P. 2004. Gene recruitment of the activated INO1 locus to the nuclear membrane. PLoS Biol. 2: e342. doi: 10.1371/journal.pbio.0020342.

Brickner, D.G., Cajigas, I., Fondufe-Mittendorf, Y., Ahmed, S., Lee, P.C., Widom, J., and Brickner, J.H. 2007. H2A.Z-mediated localization of genes at the nuclear periphery confers epigenetic memory of previous transcriptional state. PLoS Biol. 5: e81. doi: 10.1371/journal.pbio.0050081.

Cabal, G.G., Genovesio, A., Rodriguez-Navarro, S., Zimmer, C., Gadal, O., Lesne, A., Buc, H., Feuerbach-Fournier, F., OlivoMarin, J.C., Hurt, E.C., et al. 2006. SAGA interacting factors confine subdiffusion of transcribed genes to the nuclear envelope. Nature 441: 770-773.
Casolari, J.M., Brown, C.R., Drubin, D.A., Rando, O.J., and Silver, P.A. 2005. Developmentally induced changes in transcriptional program alter spatial organization across chromosomes. Genes \& Dev. 19: 1188-1198.

Dhasarathy, A. and Kladde, M.P. 2005. Promoter occupancy is a major determinant of chromatin remodeling enzyme requirements. Mol. Cell. Biol. 25: 2698-2707.

Dower, K., Kuperwasser, N., Merrikh, H., and Rosbash, M. 2004. A synthetic A tail rescues yeast nuclear accumulation of a ribozymeterminated transcript. RNA 10: 1888-1899.

Drubin, D.A., Garakani, A.M., and Silver, P.A. 2006. Motion as a phenotype: The use of live-cell imaging and machine visual screening to characterize transcription-dependent chromosome dynamics. BMC Cell Biol. 7: 19.

Dudley, A.M., Rougeulle, C., and Winston, F. 1999. The Spt components of SAGA facilitate TBP binding to a promoter at a post-activator-binding step in vivo. Genes \& Dev. 13: 2940-2945.

Fasken, M.B. and Corbett, A.H. 2005. Process or perish: Quality control in mRNA biogenesis. Nat. Struct. Mol. Biol. 12: $482-488$.

Fischer, T., Strasser, K., Racz, A., Rodriguez-Navarro, S., Oppizzi, M., Ihrig, P., Lechner, J., and Hurt, E. 2002. The mRNA export machinery requires the novel Sac3p-Thplp complex to dock at the nucleoplasmic entrance of the nuclear pores. EMBO J. 21: 58435852.

Fischer, T., Rodriguez-Navarro, S., Pereira, G., Racz, A., Schiebel, E., and Hurt, E. 2004. Yeast centrin Cdc31 is linked to the nuclear mRNA export machinery. Nat. Cell Biol. 6: 840-848.

Gallardo, M., Luna, R., Erdjument-Bromage, H., Tempst, P., and Aguilera, A. 2003. Nab2p and the Thp1p-Sac3p complex functionally interact at the interface between transcription and mRNA metabolism. J. Biol. Chem. 278: 24225-24232.

Goldstein, A.L. and McCusker, J.H. 1999. Three new dominant drug resistance cassettes for gene disruption in Saccharomyces cerevisiae. Yeast 15: 1541-1553.

Grant, P.A., Duggan, L., Cote, J., Roberts, S.M., Brownell, J.E., Candau, R., Ohba, R., Owen-Hughes, T., Allis, C.D., Winston, F., et al. 1997. Yeast Gcn5 functions in two multisubunit complexes to acetylate nucleosomal histones: Characterization of an Ada complex and the SAGA (Spt/Ada) complex. Genes \& Dev. 11: $1640-1650$.

Hieronymus, H., Yu, M.C., and Silver, P.A. 2004. Genome-wide mRNA surveillance is coupled to mRNA export. Genes \& Dev. 18: 2652-2662.

Hilleren, P., McCarthy, T., Rosbash, M., Parker, R., and Jensen, T.H. 2001. Quality control of mRNA $3^{\prime}$-end processing is linked to the nuclear exosome. Nature 413: 538-542.

Huh, W.K., Falvo, J.V., Gerke, L.C., Carroll, A.S., Howson, R.W., Weissman, J.S., and O'Shea, E.K. 2003. Global analysis of protein localization in budding yeast. Nature 425: 686-691.

Jensen, T.H., Boulay, J., Rosbash, M., and Libri, D. 2001a. The DECD box putative ATPase Sub2p is an early mRNA export factor. Curr. Biol. 11: 1711-1715.

Jensen, T.H., Patricio, K., McCarthy, T., and Rosbash, M. 2001b. A block to mRNA nuclear export in S. cerevisiae leads to hyperadenylation of transcripts that accumulate at the site of transcription. Mol. Cell 7: 887-898.

Jensen, T.H., Dower, K., Libri, D., and Rosbash, M. 2003. Early formation of mRNP: License for export or quality control? Mol. Cell 11: 1129-1138.

Kohler, A., Pascual-Garcia, P., Llopis, A., Zapater, M., Posas, F., Hurt, E., and Rodriguez-Navarro, S. 2006. The mRNA export factor Sus1 is involved in Spt/Ada/Gcn5 acetyltransferase-mediated $\mathrm{H} 2 \mathrm{~B}$ deubiquitinylation through its interaction with Ubp8 and Sgf11. Mol. Biol. Cell 17: 4228-4236.

Lei, E.P., Stern, C.A., Fahrenkrog, B., Krebber, H., Moy, T.I., Aebi, U., and Silver, P.A. 2003. Sac3 is an mRNA export factor that localizes to cytoplasmic fibrils of nuclear pore complex. Mol. Biol. Cell 14: 836-847. 
Libri, D., Dower, K., Boulay, J., Thomsen, R., Rosbash, M., and Jensen, T.H. 2002. Interactions between mRNA export commitment, $3^{\prime}$-end quality control, and nuclear degradation. Mol. Cell. Biol. 22: 8254-8266.

Menon, B.B., Sarma, N.J., Pasula, S., Deminoff, S.J., Willis, K.A., Barbara, K.E., Andrews, B., and Santangelo, G.M. 2005. Reverse recruitment: the Nup84 nuclear pore subcomplex mediates Rap1/Gcr1/Gcr2 transcriptional activation. Proc. Natl. Acad. Sci. 102: 5749-5754.

Rodriguez-Navarro, S., Fischer, T., Luo, M.J., Antunez, O., Brettschneider, S., Lechner, J., Perez-Ortin, J.E., Reed, R., and Hurt, E. 2004. Sus1, a functional component of the SAGA histone acetylase complex and the nuclear pore-associated mRNA export machinery. Cell 116: 75-86.

Schmid, M., Arib, G., Laemmli, C., Nishikawa, J., Durussel, T., and Laemmli, U.K. 2006. Nup-PI: The nucleopore-promoter interaction of genes in yeast. Mol. Cell 21: 379-391.

Sikorski, R.S. and Hieter, P. 1989. A system of shuttle vectors and yeast host strains designed for efficient manipulation of DNA in Saccharomyces cerevisiae. Genetics 122: 19-27.
Sterner, D.E., Grant, P.A., Roberts, S.M., Duggan, L.J., Belotserkovskaya, R., Pacella, L.A., Winston, F., Workman, J.L., and Berger, S.L. 1999. Functional organization of the yeast SAGA complex: Distinct components involved in structural integrity, nucleosome acetylation, and TATA-binding protein interaction. Mol. Cell. Biol. 19: 86-98.

Taddei, A., Van Houwe, G., Hediger, F., Kalck, V., Cubizolles, F., Schober, H., and Gasser, S.M. 2006. Nuclear pore association confers optimal expression levels for an inducible yeast gene. Nature 441: 774-778.

Tong, A. and Boone, C. 2007. High-throughput strain construction and systematic synthetic lethal screening in Saccharomyces cerevisiae. In Methods in microbiology: Yeast gene analysis, 2nd ed. (eds., I. Stansfield and M.J.R. Stark), Vol. 36, pp. 369-386, 706-707. Elsevier, Amsterdam.

Tong, A.H., Evangelista, M., Parsons, A.B., Xu, H., Bader, G.D., Page, N., Robinson, M., Raghibizadeh, S., Hogue, C.W., Bussey, H., et al. 2001. Systematic genetic analysis with ordered arrays of yeast deletion mutants. Science 294: 2364-2368. 

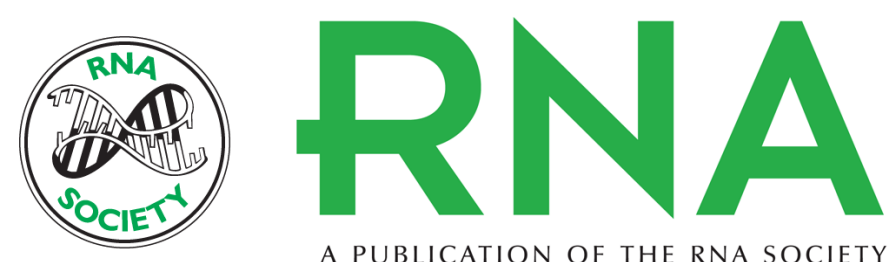

A PUBLICATION OF THE RNA SOCIETY

\section{Sus1, Sac3, and Thp1 mediate post-transcriptional tethering of active genes to the nuclear rim as well as to non-nascent mRNP}

Julia A. Chekanova, Katharine C. Abruzzi, Michael Rosbash, et al.

RNA 2008 14: 66-77

References This article cites 36 articles, 17 of which can be accessed free at: http://rnajournal.cshlp.org/content/14/1/66.full.html\#ref-list-1

\section{License}

Email Alerting Service

Receive free email alerts when new articles cite this article - sign up in the box at the top right corner of the article or click here. 